\title{
Thermal Decomposition Behaviour of Fine Iron Ore Particles
}

\author{
Yingxia QU, ${ }^{1) *}$ Yongxiang YANG ${ }^{2)}$ Zongshu ZOU, ${ }^{1)}$ Christiaan ZEILSTRA, ${ }^{3)}$ Koen MEIJER $^{3)}$ and Rob BOOM ${ }^{2)}$ \\ 1) School of Materials and Metallurgy, Northeastern University, Box 312, NO. 3-11, Wenhua Road, Heping District, 110819 , \\ Shenyang, P. R. China. $\quad$ 2) Department of Materials Science and Engineering, Delft University of Technology, Mekelweg \\ 2, 2628 CD Delft, the Netherlands. $\quad 3$ 3) Tata Steel, 1970 CA IJmuiden, the Netherlands.
}

(Received on April 9, 2014; accepted on May 28, 2014)

\begin{abstract}
In the smelting cyclone of Hlsarna process, both thermal decomposition and gaseous reduction of iron ore contribute to the expected pre-reduction degree about $20 \%$. However, the fine ore reduction and melting process in the smelting cyclone is extremely fast and it is very difficult to differentiate between the thermal decomposition and gaseous reduction. This study focused on the thermal decomposition mechanism of the fine iron ore under different conditions. Firstly, the theoretical evaluation has been conducted based on the thermodynamics, and then the laboratory investigation was conducted in three stages with three reactors: the TGA-DSC, the electrically heated horizontal tube furnace and the High-temperature Drop Tube Furnace (HDTF). According to the experimental results of the first two stages and the theoretical evaluation, it was found that the temperature of intensive thermal decomposition of $\mathrm{Fe}_{2} \mathrm{O}_{3}$ in the inert gas environment is in the range of $1473-1573 \mathrm{~K}$, while the thermal decomposition of $\mathrm{Fe}_{3} \mathrm{O}_{4}$ could be sped up when the temperature is above $1773 \mathrm{~K}$ in the inert gas. Temperature plays an important role in the thermal decomposition degree and reaction rate. Finally, it was found that the thermal decomposition of the individual iron ore particles took place very rapidly in the HDTF and no significant influence of the particle size and residence time ( $t \leq 2020 \mathrm{~ms}$ ) on the equivalent reduction degree could be observed, when the particle diameter was smaller than $250 \mu \mathrm{m}$ in the $\mathrm{CO}_{2}$ gas.
\end{abstract}

KEY WORDS: HIsarna process; smelting reduction; fine iron ore particles; high temperature; thermal decomposition.

\section{Introduction}

Nowadays the blast furnace process is still the primary iron making technology. For achieving a more efficient operation from an energy and economic point of view, various revolutionary technologies are now developed as alternative ironmaking processes such as COREX and FINEX already in commercial operation, Circosmelt and HIsarna ${ }^{1,2)}$ under development. HIsarna, as shown in Fig. 1, is one of these promising technologies under intensive development, based on smelting reduction principles. It is the technology which has the potential to reduce emissions of carbon dioxide $\left(\mathrm{CO}_{2}\right)$ compared to the blast furnace steelmaking route by more than $50 \%{ }^{3)}$ The core of the process consists of three reactors, a smelting cyclone, a smelting reduction vessel (SRV) and a coal pyrolyser. Due to the high temperatures in the furnace, fine iron ore particles are melted in the smelting cyclone. The melt is collected on the water-cooled sidewalls of the cyclone section, runs down the wall and drops into the liquid bath in the SRV where the final reduction is completed. The original iron ore particles are injected into the cyclone reactor and pre-reduced to a reduction degree of about $20 \%$ through thermal decomposition and reduction by the post-combustion gases arising from the SRV. Up to now,

* Corresponding author: E-mail: quyingxia800@163.com

DOI: http://dx.doi.org/10.2355/isijinternational.54.2196 most of the previous studies ${ }^{4-6)}$ focused on the mechanisms of the gas-hematite reaction at low temperature and the gaswüstite reaction at high temperature with the background of the blast furnace process. The hematite decomposition was usually neglected because of the requirement of the higher temperature than gas-hematite reduction.

The smelting cyclone of the HIsarna process is a complicated high temperature reactor. In the smelting cyclone, the temperature is extremely high and the size of the iron ore particles is very small. The smelting cyclone provides a suitable environment for the thermal decomposition of iron ore particles. Although oxygen is injected into the cyclone together with iron ore particles, it preferably reacts with carbon monoxide and hydrogen rapidly and generates sufficient energy to produce a large amount of energy which heats the particles and the gas quickly. The fine iron oxide particles in the smelting cyclone experience a series of physical and chemical changes including rapid heating up, thermal decomposition, gas-solid particle reduction, melting, and gas-molten particle reduction. For that all the processes are extremely fast and it is very difficult to differentiate between the thermal decomposition and gaseous reduction. It is a fundamental question whether the thermal decomposition of hematite in the cyclone could be an important factor of determining the pre-reduction degree (about 20\%) of iron ore. From the thermodynamics point of view, the products of the thermal decomposition and reduction are the same 

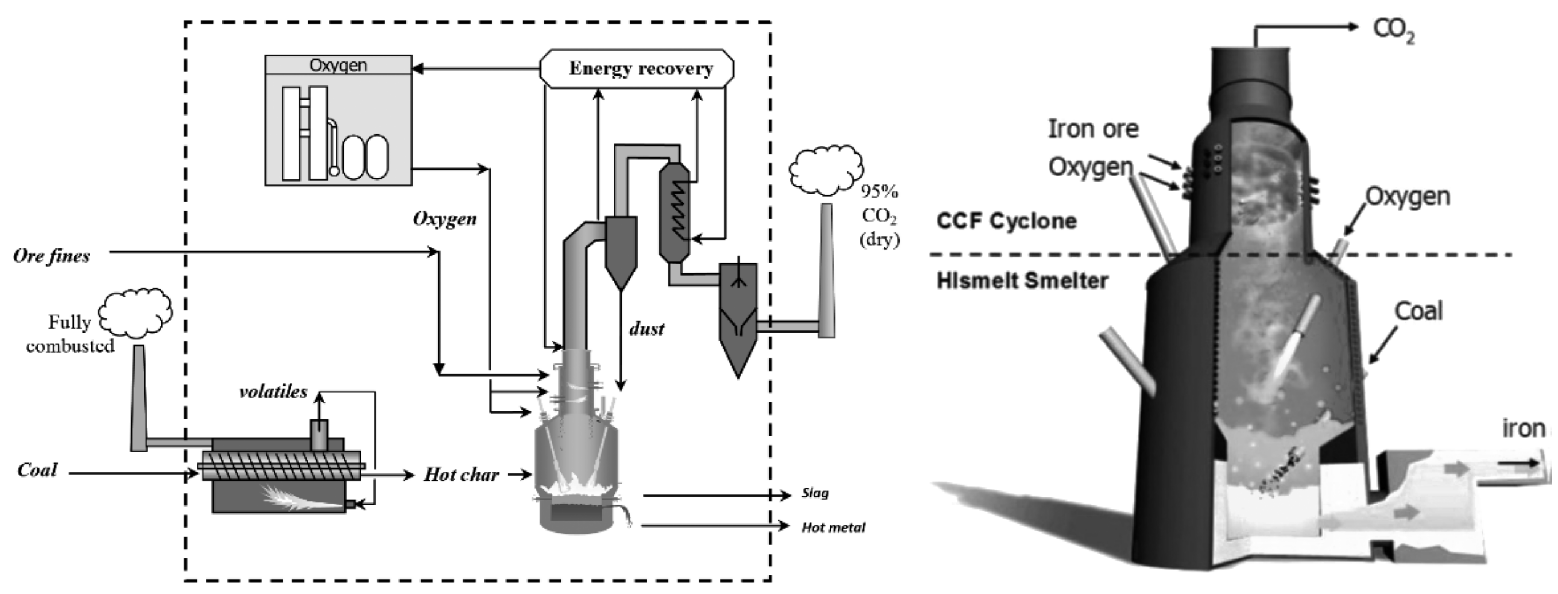

Fig. 1. Schematic diagram of the HIsarna process. ${ }^{7,8)}$

because both of the processes remove oxygen from the high oxygen concentration iron oxides and generate the low oxygen concentration iron oxides. However, from the kinetics point of view, the required reaction conditions and reaction rates are different. In order to obtain a comprehensive and clear understanding of the iron ore behaviour in the smelting cyclone, the laboratory experiments on thermal decomposition of iron ore particles has been carried out. On the other hand, as that the smelting cyclone and SRV have a close contact and the reactions in the smelting cyclone would directly affect the operation parameters in the SRV. Therefore, the kinetic study of the thermal decomposition of iron ore under the conditions of the smelting cyclone will be helpful to optimize the whole HIsarna process.

\section{Theoretical Evaluation}

There are three main forms of iron oxides: hematite $\left(\mathrm{Fe}_{2} \mathrm{O}_{3}\right)$, magnetite $\left(\mathrm{Fe}_{3} \mathrm{O}_{4}\right)$ and wüstite $(\mathrm{FeO})$, and their melting points are $1838 \mathrm{~K}, 1870 \mathrm{~K}$ and $1644 \mathrm{~K}$, respectively. According to the literature, the thermal decomposition of hematite ore has been mentioned in some laboratory experiments. For example, Gilles ${ }^{9)}$ stated that the highest oxide form is unstable above $1810 \mathrm{~K}$ and it decomposes into gaseous oxygen and an oxide containing $71.6 \%$ iron which is close to the composition of magnetite. This reaction was also mentioned in the study of Nakamura et al. ${ }^{10)}$ in 1981. A laboratory-scale test was made, in which iron oxide contained in a water-cooled crucible was melted and reduced by using $10-15 \% \mathrm{H}_{2}-\mathrm{Ar}$ transferred arc plasma. It was stated that at high temperatures, the oxygen removed by thermal decomposition before the start of the reduction corresponds to a degree of reduction of about $18 \%$. The equation for calculating the equivalent reduction degree $R$ due to thermal decomposition $^{11)}$ and thermal decomposition reactions of iron oxides are as follows.

$$
\begin{array}{r}
R=\frac{\Delta m_{\text {oxygen }}}{m_{\text {tot-oxygen }}} \ldots \ldots \ldots \ldots . . . . . . . . \\
6 \mathrm{Fe}_{2} \mathrm{O}_{3}(\mathrm{~s})=4 \mathrm{Fe}_{3} \mathrm{O}_{4}(\mathrm{~s})+\mathrm{O}_{2}(\mathrm{~g}) \\
\Delta G^{o}=500600-280.7 \mathrm{~T}
\end{array}
$$

$$
\begin{gathered}
2 \mathrm{Fe}_{3} \mathrm{O}_{4}(\mathrm{~s})=6 \mathrm{FeO}(\mathrm{l})+\mathrm{O}_{2}(\mathrm{~g}) \\
\Delta G^{o}=858200-392.6 T \\
\mathrm{FeO}(\mathrm{l})=\mathrm{Fe}(\mathrm{l})+\mathrm{O}_{2}(\mathrm{~g}) \\
\Delta G^{o}=256061-53.681 T
\end{gathered}
$$

The equivalent reduction degree $R$ of the iron ore is defined as the ratio of weight loss of oxygen $\Delta m_{\text {oxygen }}$ to the total initial mass of oxygen in the iron oxides in the iron ore sample $m_{\text {tot-oxygen }}$ as shown in Eq. (1). The reversible reactions and their standard Gibbs free energy $(\mathrm{J} /(\mathrm{mol} \cdot \mathrm{K}))$ are shown in Eqs. (2)-(4). ${ }^{12)}$ According to the definition of Eq. (1), it can be calculated that when $\mathrm{Fe}_{2} \mathrm{O}_{3}$ decomposes to $\mathrm{Fe}_{3} \mathrm{O}_{4}$ completely, the equivalent reduction degree is $11.11 \%$. When $\mathrm{Fe}_{2} \mathrm{O}_{3}$ decomposes to $\mathrm{FeO}$ completely, the equivalent reduction degree is $33.33 \%$. Finally when $\mathrm{Fe}_{2} \mathrm{O}_{3}$ decomposes to Fe completely, the equivalent reduction degree is $100 \%$. At a given temperature, the direction of a reaction can be judged by calculating the Gibbs free energy $\Delta G(\mathrm{~J} /(\mathrm{mol} \cdot \mathrm{K}))$ as shown in Eq. (5). If $\Delta G=0$, the reactions achieve an equilibrium state. The equilibrium state at each temperature has an equilibrium oxygen partial pressure. In other words, the start temperature of thermal decomposition is dependent on the partial pressure of oxygen in the reaction system. The equilibrium partial pressure of oxygen of the three iron oxides can be calculated from Eq. (6) which is derived by substituting Eq. (2) or (3) or (4) into Eq. (5).

$$
\begin{gathered}
\Delta G=\Delta G^{o}+R_{g} T \ln \frac{p_{o_{2}}}{p^{o}} \\
\ln \frac{p_{o_{2}}}{p^{o}}=\frac{-\Delta G^{o}}{R_{g} T} \ldots \ldots . .
\end{gathered}
$$

Where,

$\Delta G^{o}$ - the standard Gibbs free energy $(\mathrm{J} /(\mathrm{mol} \cdot \mathrm{K}))$

$p^{o} \quad$ - the reference pressure in the system $(\mathrm{Pa})$

$p_{o_{2}}$ - the partial pressure of oxygen $(\mathrm{Pa})$

$R_{g} \quad$ - the universal gas constant $\left(R_{g}=8.314 \mathrm{~J} /(\mathrm{mol} \cdot \mathrm{K})\right)$

Since the reaction furnace in this study is an open system, the reference pressure $\left(p^{o}\right)$ of the system is about $1 \mathrm{~atm}$. Figure 2 was made according to Eq. (5) based on the reference pressure of $1 \mathrm{~atm}$. It shows that the equilibrium partial pres- 
sure of oxygen $\left(p_{o_{2}}\right)$ as a function of temperature for hematite, magnetite and wüstite, increases with the increase of temperature. The calculation results for the case of hematite show that when the $p_{o_{2}}$ in the system is $0 \mathrm{~Pa}$, the reaction would take place at room temperature. It was found that at $1473 \mathrm{~K}$, the thermal decomposition of hematite can take place only if the $p_{o_{2}}$ is less than $82 \mathrm{~Pa}$ which is about $0.08 \%$ of $1 \mathrm{~atm}$. At $1573 \mathrm{~K}$, the thermal decomposition of hematite can take place if the $p_{o_{2}}$ is less than $1107 \mathrm{~Pa}$ which is about $1.1 \%$ of $1 \mathrm{~atm}$. Figure 2 reveals that above about $1500 \mathrm{~K}$, the equilibrium $p_{o_{2}}$ increases rapidly with the increase of temperature. It means that if the $p_{o_{2}}$ in the reaction system is controlled close to be less than equilibrium partial pressure, the thermal decomposition of hematite will accelerate at above $1500 \mathrm{~K}$. It can also be calculated that the boiling temperature of the thermal decomposition of hematite in an open system is $1783 \mathrm{~K}$, at which temperature hematite could decompose intensively with $p_{o_{2}}$ of $1 \mathrm{~atm}$. The thermal decomposition of magnetite is much more difficult than that of hematite. Although the thermal decomposition of magnetite can also take place when the $p_{o_{2}}$ is $0 \mathrm{~Pa}$, according to the thermodynamic calculation, the equilibrium $p_{o_{2}}$ only has slight increase between $1673 \mathrm{~K}$ and $1773 \mathrm{~K}$. However, it has an obvious increase from $1773 \mathrm{~K}$ to $1873 \mathrm{~K}$. The boiling temperature of the thermal decomposition of magnetite in an open system is $2186 \mathrm{~K}$. The decomposition of wüstite is the most difficult process as shown in Fig. 2. Below the temperature of $2200 \mathrm{~K}$, the equilibrium partial pressures are almost always kept at the value of zero. If the temperature is $4770 \mathrm{~K}$, the equilibrium $p_{\mathrm{O}_{2}}$ can reach $1 \mathrm{~atm}$, which is much higher than hematite (1783 K) and magnetite (2 186 K).

\section{Experimental}

\subsection{Experimental Strategy}

The actual equivalent reduction degree of hematite ore caused by thermal decomposition in the cyclone furnace is difficult to estimate because of the complicated environment. The laboratory experimental study of the thermal decomposition of hematite ore has been conducted in three methods with three different reactors, and 4 influential factors (temperature, gas composition, particle size, and residence time) were investigated.

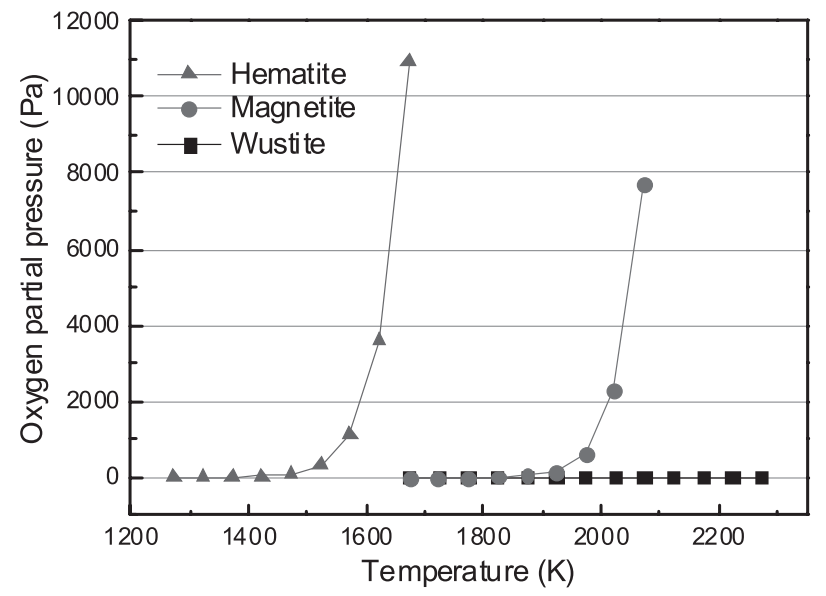

Fig. 2. Equilibrium of oxygen partial pressure as a function of temperature for hematite, magnetite and wüstite.
Method 1: Thermal decomposition of hematite ore with a TGA-DSC analyser with an inert gas flow (small sample size: $80 \mathrm{mg}$; 293-1 $753 \mathrm{~K}$; $p_{o_{2}} \approx 0 \mathrm{~Pa}$ ); Aim: observe the thermal decomposition at elevated temperature.

Method 2: Thermal decomposition of hematite ore at different temperatures with an electrically heated horizontal furnace with inert carrier gas (larger sample size: 10 grams; $1673 \mathrm{~K}, 1773 \mathrm{~K}, 1873 \mathrm{~K} ; p_{o_{2}} \approx 0 \mathrm{~Pa}$ ); Aim: confirm the results with TGA-DSC analyser and obtain the accurate equivalent reduction degree.

Method 3: Thermal decomposition of hematite ore in different inert gas compositions, with different particle sizes, and residence time in a HDTF (individual particles: total sample size of 3 grams; $1550 \mathrm{~K}, 1600 \mathrm{~K}, 1650 \mathrm{~K}$, $1700 \mathrm{~K}, 1750 \mathrm{~K}, 1800 \mathrm{~K}$; $p_{o_{2}} \approx 0 \mathrm{~Pa}$ ); Aim: study the in-flight thermal decomposition behaviour and provide more direct information for the HIsarna cyclone reactor.

\subsection{Experimental Set-up and Conditions}

\subsubsection{Materials}

The raw material of the dry iron ore used in the experiment was provided by Tata Steel in IJmuiden, the Netherlands as shown in Table 1. The hematite content is as high as $94.9 \%$. The raw material was prepared by sieving to get different size groups of particles and then dried to remove the moisture.

\subsubsection{Experiments with the TGA-DSC}

The first stage of the experiments has been carried out by using a thermogravimetric analyzer TGA-DSC (NETZSCH Thermal Analysis STA 409). The inert gas of $\mathrm{N}_{2}$ (purity: $99.999 \%$ ) was controlled by a mass flow meter to protect the sample. The sample holder is a cylindrical crucible which has the volume of $85 \mu \mathrm{l}$. This study focused on the thermal decomposition behaviour of hematite ore at elevated temperature. The experimental conditions are shown in Table 2.

\subsubsection{Experiments with the Horizontal Tube Furnace}

The sample size in the TGA-DSC analyser is too small $(\sim 80 \mathrm{mg})$ to do chemical analysis or other tests. The experiments were further carried out in the horizontal tube furnace at pre-selected isothermal temperatures as shown in

Table 1. Hematite ore composition.

\begin{tabular}{crcc}
\hline Composition & Mass\% & Composition & Mass\% \\
\hline $\mathrm{Al}_{2} \mathrm{O}_{3}$ & 0.845 & $\mathrm{Mn}$ & 0.147 \\
$\mathrm{CaO}$ & 0.015 & $\mathrm{SiO}_{2}$ & 2.800 \\
$\mathrm{Fe}_{2} \mathrm{O}_{3}$ & 94.935 & Rest & 1.228 \\
$\mathrm{MgO}$ & 0.030 & - & - \\
\hline
\end{tabular}

Table 2. Experimental condition in the TGA-DSC analysis.

\begin{tabular}{ll}
\hline Experimental condition & \multicolumn{1}{c}{ Operating parameters } \\
\hline Sample & Hematite ore: $\mathrm{Fe}_{2} \mathrm{O}_{3} 94.9 \%$ \\
Holding time $(\mathrm{h})$ & 4 \\
Heating rate $(\mathrm{K} / \mathrm{min})$ & 10 \\
Particle size $(\mu \mathrm{m})$ & Hematite ore: $45-53,125-250$ \\
Temperature $(\mathrm{K})$ & $293-1753$ \\
\hline
\end{tabular}


Fig. 3. A larger sample size could be used to obtain an accurate equivalent reduction degree. The experimental conditions are listed in Table 3. The temperature at the isothermal zone was measured by a type $\mathrm{S}$ thermocouple. From this experiment, the maximum equivalent reduction degree of hematite ore at a certain temperature and in a certain holding time (keeping $p_{o_{2}} \approx 0$ ) has been obtained. Only the small particle size of hematite ore was used in the experiment. When the holding time is long enough, the particle size doesn't play an important role in the final equivalent reduction degree. During the experiment, high purity of $\mathrm{N}_{2}$ gas has been used as protection gas. After the experiment, the

Table 3. Experimental condition in the horizontal furnace.

\begin{tabular}{ll}
\hline Experimental condition & \multicolumn{1}{c}{ Operating parameters } \\
\hline Sample & Hematite ore: $\mathrm{Fe}_{2} \mathrm{O}_{3} 94.9 \%$ \\
Holding time $(\mathrm{h})$ & $1,2,3$ \\
Heating rate $(\mathrm{K} / \mathrm{min})$ & 10 \\
Particle size $(\mu \mathrm{m})$ & Hematite ore: $45-53$ \\
Temperature $(\mathrm{K})$ & $1673,1773,1873$ \\
\hline
\end{tabular}

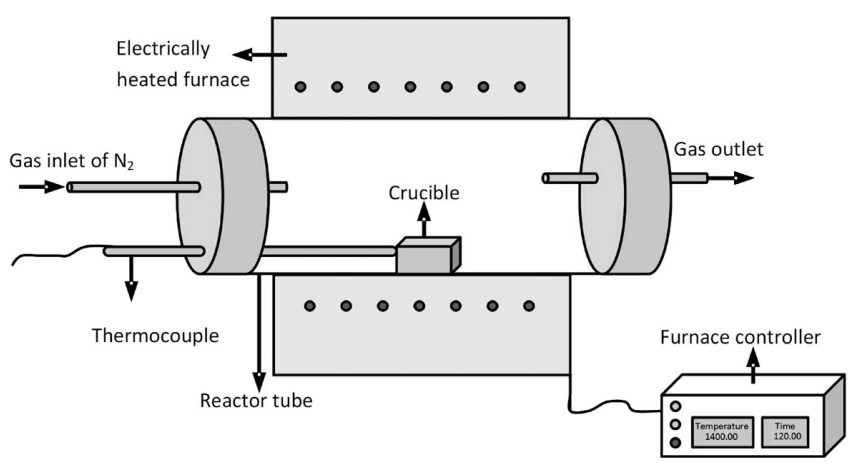

Fig. 3. Schematic diagram of the electrically heated horizontal tube furnace. sample was grinded into powder for the further analysis with chemical titration.

\subsubsection{Experiments with the HTDF}

In this study, the thermal decomposition behaviour of the hematite ore has been further explored with the HDTF. The schematic drawing of the experimental set-up is shown in Fig. 4. The laboratory experimental set-up of the HDTF was normally used in the study of coal combustion behaviour. ${ }^{13-15)}$ The core of the experimental set-up mainly consists of 6 facilities: an electrically heated tube furnace, a syringe pump particle feeder, a particle injection probe, a sampling probe, a gas pre-heater and a sample collector. The injection probe and sampling probe are made of high temperature resistance stainless steel. The alumina tube with inside diameter of $60 \mathrm{~mm}$, outside diameter of $70 \mathrm{~mm}$ and length of $1100 \mathrm{~mm}$ was used as the reactor tube (volume: $3.1 \mathrm{~L}$ ). After the starting of the experiment, a continuous flow of inert gas from the gas cylinder was regulated by a mass flow controller. The typical gas flow rate was $4 \mathrm{~L} / \mathrm{min}$. A small part of the gas was separated as carrier gas which was measured by a mass flow meter. The carrier gas flowed into the glass tube of the particle feeder and brought several particles together with it, and then flowed into the water cooled injection probe. The remaining gas was preheated to $773 \mathrm{~K}$, and then introduced into the reactor directly from the top of the furnace. The thermal decomposition took place in the hot zone of the furnace which starts from the tip of the injection probe and ends at the top of the sampling probe. The reacted particles and gas were received by the water cooled and gas quenched sampling probe. Finally, the particles were collected in the sample collector. The temperature distribution at the hot zone is shown in Fig. 5 with three examples: $1600 \mathrm{~K}$, $1650 \mathrm{~K}$ and $1700 \mathrm{~K}$.

The experimental conditions are shown in Table 4. The effects of gas, temperature, residence time, and particle size on the iron ore thermal decomposition have been studied in

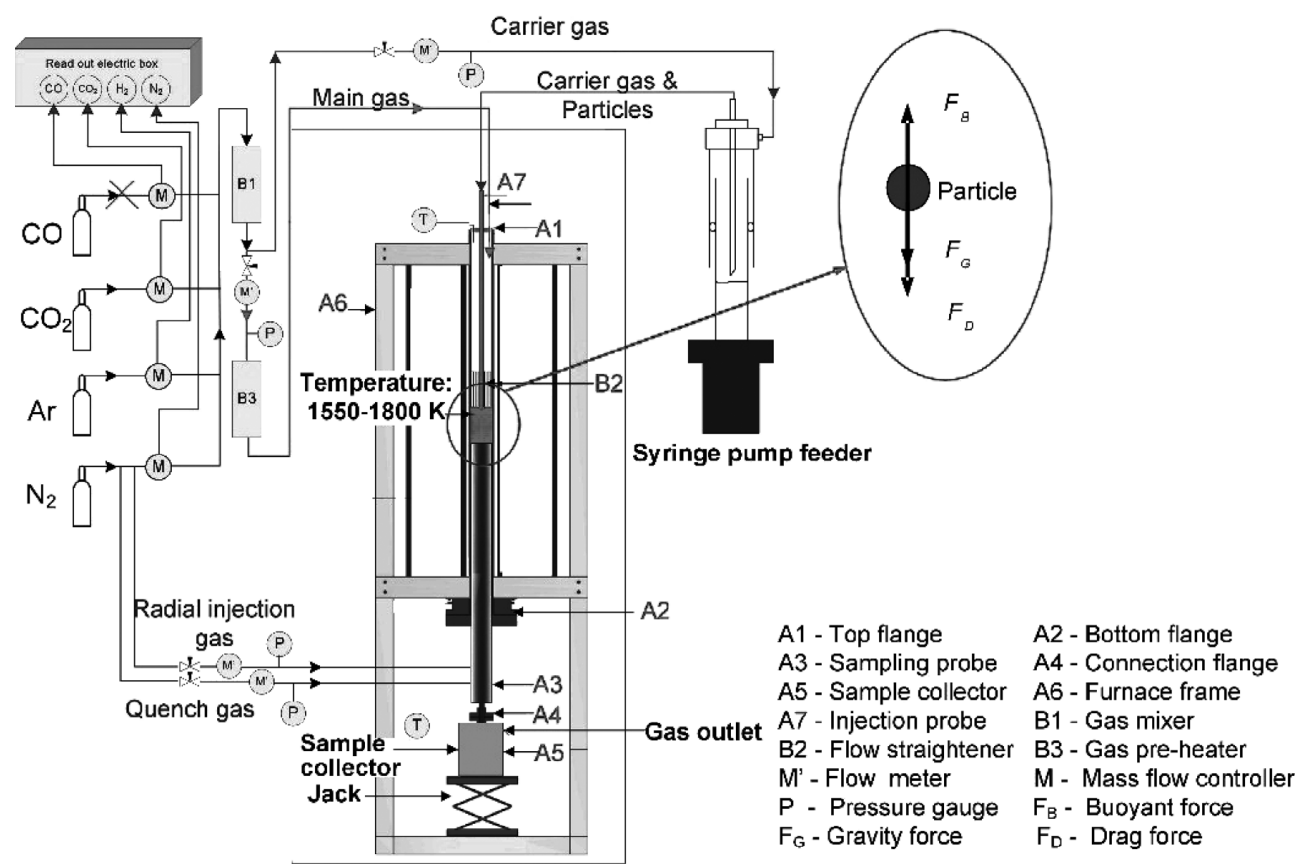

Fig. 4. Schematic diagram of the High-temperature Drop Tube Furnace (HTDF). 
the HTDF. The inert gas (purity: 99.999\%) was changed from the symmetric molecule gas $\mathrm{N}_{2}$ to monoatomic gas $\mathrm{Ar}$, and then to the asymmetric molecule gas $\mathrm{CO}_{2}$. The temperature was changed from $1550 \mathrm{~K}$ to $1800 \mathrm{~K}$. The residence time was varied from $210 \mathrm{~ms}$ to $2020 \mathrm{~ms}$, which was calculated by applying Newton's second law of motion and Stokes law to the particles' motion through fluids. It was assumed that there were three forces acting on a single particle: gravity force, buoyancy force and drag force. The six particle sizes have been tested, which are in the overall range of $38-250 \mu \mathrm{m}$. To prevent the thermal shock and extend the service life of the reactor tube and heating elements, the heating rate of the furnace was set to $3 \mathrm{~K} / \mathrm{min}$ and the cooling rate was set to $2 \mathrm{~K} / \mathrm{min}$.

\section{Results and Discussion}

\subsection{Experiments in the TGA-DSC}

Firstly, a series of experiments have been carried out with

Table 4. Experimental conditions in the HTDF.

\begin{tabular}{ll}
\hline Experimental condition & \multicolumn{1}{c}{ Operating parameters } \\
\hline Sample & Hematite ore: $\mathrm{Fe}_{2} \mathrm{O}_{3} 94.9 \%$ \\
Particle feed rate $(\mathrm{g} / \mathrm{h})$ & 1 \\
Gas composition & $100 \% \mathrm{~N}_{2} ; 100 \% \mathrm{Ar} ; 100 \% \mathrm{CO}_{2}$ \\
Particle size $(\mu \mathrm{m})$ & $38-45,45-53,53-75,75-90,90-125,125-250$ \\
Residence time $(\mathrm{ms})$ & $210,970,2020$ \\
Temperature $(\mathrm{K})$ & $1550,1600,1650,1700,1750,1800$ \\
\hline
\end{tabular}

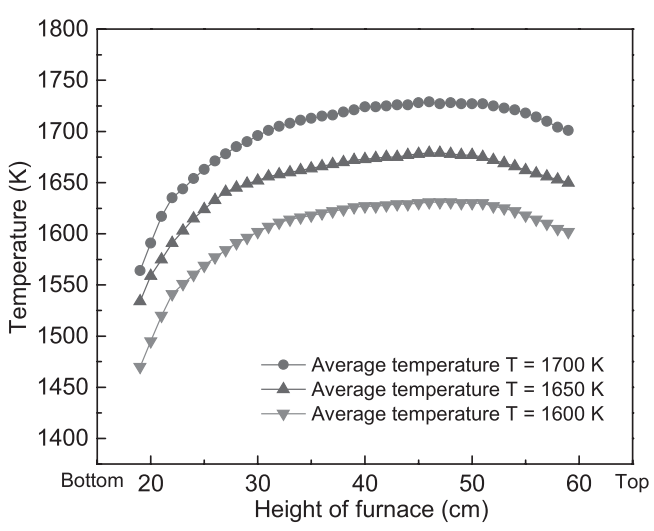

Fig. 5. Temperature profiles at the hot zone.
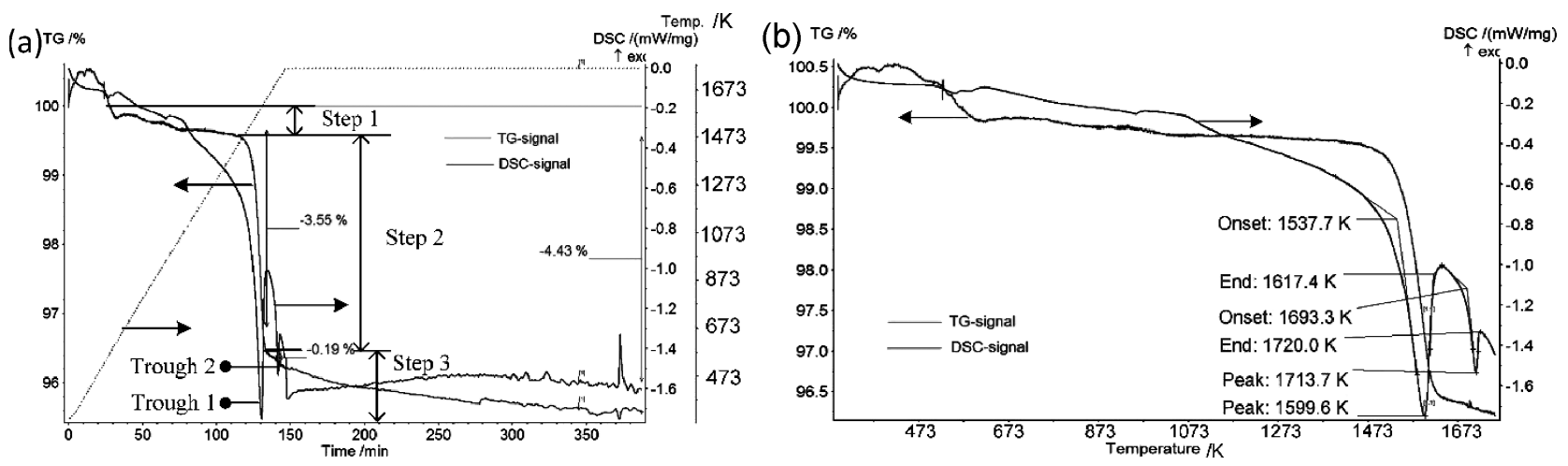

Fig. 6. TG-DSC analysis of hematite ore (Heating rate: $10 \mathrm{~K} / \mathrm{min}$ ) (a) as a function of time, (b) as a function of temperature.

hematite ore with different particle sizes and heating rates. Figure 6 shows the TG and DSC profiles of one test. The weight of the sample was $80.2 \mathrm{mg}$ and the particle size was in the range of $45-53 \mu \mathrm{m}$. The highest temperature achieved was $1753 \mathrm{~K}$ and the heating rate was set at $10 \mathrm{~K} / \mathrm{min}$. In Fig. 6(a), the temperature history in the furnace is presented by the red line. It was linearly increased to the maximum temperature and then held for 4 hours. There are three steps on the TG curve and two troughs on the DSC curve before the holding time. Due to that the device was not stable at the beginning of the test (0-30 min.), the TG value was a little more than $100 \%$. The total weight loss of the sample is about $4.43 \%$. A slight weight loss appears at the first stage of the heating time (30-120 min.) due to the thermal decomposition of a small quantity of hematite. The thermal decomposition of hematite is endothermic reaction. It is the reason why the DSC curve goes down below zero.

The slight weight loss at the beginning of the heating time (30-120 min.) is followed by the sharp weight loss (at about $130 \mathrm{~min}$.). The total weight loss at the end of the stage of sharp weight loss is around $3.55 \%$. Firstly, it indicates that hematite is not stable with the increase of temperature in the inert gas, which is in agreement with the theoretical evaluation perfectly. Hematite started to decompose slowly with the increase of temperature in the first stage (heating time: 0-120 min. and temperature: 298-1473 K), while the decomposition rate was accelerated when temperature was raised above around $1473 \mathrm{~K}$ and the sharp weight loss was obtained. Secondly, the stage of sharp weight loss is corresponding to the first big trough on the DSC curve which means that the mass loss was caused by an endothermic reaction of the thermal decomposition of hematite. Further more, the reaction enthalpy of thermal decomposition of 1 mol $\mathrm{Fe}_{2} \mathrm{O}_{3}$ is about $78.24 \mathrm{~kJ} / \mathrm{mol}\left(\Delta H_{298}\right)$ at $298 \mathrm{~K}$ and it increases to $78.71 \mathrm{~kJ} / \mathrm{mol}\left(\Delta H_{1473}\right)$ at $1473 \mathrm{~K}$. The reaction heat only has a small increase with the increase of temperature. Therefore, the big trough on the DSC curve at the sharp weight loss stage is caused by the high decomposition rate. Thirdly, it can be calculated that if $\mathrm{Fe}_{2} \mathrm{O}_{3}$ decomposes to $\mathrm{Fe}_{3} \mathrm{O}_{4}$ completely, the weight loss is about $3.3 \%$. It means that the hematite was probably completely transferred to magnetite at the end of the sharp weight loss. The weight loss of $0.25 \%(3.55 \%-3.3 \%)$ is probably caused by the thermal decomposition of magnetite. The second trough shows that the heat absorption of the reaction during this 
period is less than the heat absorption of the reaction which results in the first trough. The weight loss during the second trough is also not obvious. By the end of the second trough, the weight loss is about $3.74 \%(3.55 \%+0.19 \%)$. For that the TGA-DSC analyser is an open system, the small amount of generated $\mathrm{O}_{2}$ could be taken away by inert gas continuously. The oxygen partial pressure in the reaction system can be kept at a very low level. Therefore, the second trough would be caused by the decomposition of magnetite or the evaporation of the other impurities in the iron ore sample. The total weight loss during the rest time is only $0.69 \%(4.43 \%-$ $3.55 \%-0.19 \%$ ), although it has a 4 hours holding time. The result shows that the weight loss decreases slowly after 200 minutes. If all the weight loss is caused by thermal decomposition of iron oxides, the equivalent reduction degree of hematite ore can be roughly estimated to be $14.8 \%$.

From Fig. 6(b), it can be clearly seen that the sharp weight loss stage is exactly marked by the big trough on the DSC curve. According to the analysis of the DSC curve, the onset and end temperatures of the first trough are $1537 \mathrm{~K}$ and $1617 \mathrm{~K}$, respectively. The point of $1537 \mathrm{~K}$ can be seen as the start temperature of thermal decomposition of the hematite ore at the sharp weight loss stage. In other words, the thermal decomposition rate of hematite is accelerated above $1537 \mathrm{~K}$. The onset and end temperatures of the second trough are $1693 \mathrm{~K}$ and $1720 \mathrm{~K}$. The start temperature of intensive thermal decomposition of hematite obtained from experiments is in agreement with the range of the theoretical evaluation. The same conclusion can be obtained that thermal decomposition of magnetite is much more difficult than the hematite.

The larger particle sized hematite ore was also tested with the TGA-DSC analyser as shown in Fig. 7. The particle size is the group of $125-250 \mu \mathrm{m}$. The heating rate is $10 \mathrm{~K} / \mathrm{min}$. The results confirmed that the thermal decomposition of hematite has a sharp weight loss stage during the heating time. The weight loss of the sharp weight loss stage is about $3.4 \%$ and the total weight loss is about $4.6 \%$ in the $4 \mathrm{~h}$ holding time. In Fig. 7(b), the start temperature of the sharp weight loss stage of hematite is about $1556 \mathrm{~K}$ and the start temperature of the second trough on the DSC curve is about $1698 \mathrm{~K}$. The two temperatures are slightly higher than the results in Fig. 6(b). It probably because that the larger particles were heated up more slowly than the small particles in the furnace.

\subsection{Experiments in the Horizontal Furnace}

The experiments in the horizontal furnace differ from the TGA-DSC analysis by the amount of the sample and the way of heating (temperature profile). TGA-DSC analysis could give the description of the ongoing process of thermal decomposition, which shows the intensive reaction temperature, exothermic reaction or endothermic reaction, and the weight loss at each moment. However, the more accurate equivalent reduction degree caused by thermal decomposition of hematite ore could not be analysed by chemical analysis, while the experimental study in the horizontal furnace could solve this problem. The larger sample size has been tested in the horizontal furnace. Chemical titration was first carried out with a certified reference material JK 29 consisting of $90.11 \%$ magnetite and $7.1 \%$ hematite, the components of which have been analyzed by a Swedish institute. Thereafter the samples in this experiment were analyzed with the accuracy of $\pm 0.2 \%$. More importantly the thermal decomposition experiments in the horizontal tube furnace were conducted at a constant temperature, and the time to reach the reaction temperature is very short (TGA-DSC tests have a constant heating rate of $10 \mathrm{~K} / \mathrm{min}$.). The temperature of the sample before pushing to the hot zone of the reactor tube is room temperature. It is similar to the actual situation.

Hematite ore was suddenly positioned at the isothermal zone of the horizontal furnace. According to the thermodynamic theory, for an open system, the released $\mathrm{O}_{2}$ is constantly removed by the flowing inert gas and maintain the real partial pressure of oxygen lower than the equilibrium value in the reactor, so the thermal decomposition reactions would not stop as long as the samples are kept in the isothermal zone. However, according to the results of TGA-DSC analysis, the reaction rate becomes very low after two hours holding time and the sharp weight loss stage was observed during the heating time (before the holding time). In order to obtain the sharp weight loss stage in the horizontal furnace, different holding time of 1 hour, 2 hours and 3 hours at $1673 \mathrm{~K}$ were tested to make sure that the total experimental time is long enough. The results shown in Fig. 8 indicate clearly that the sharp weight loss already takes place in the experiment with 1 hour holding time, and the equivalent reduction degree $(R)$ of hematite ore after 2 hours holding time increases slowly. Therefore, the holding time was fixed to 2 hours for the other experiments.

The effect of temperature on the equivalent reduction
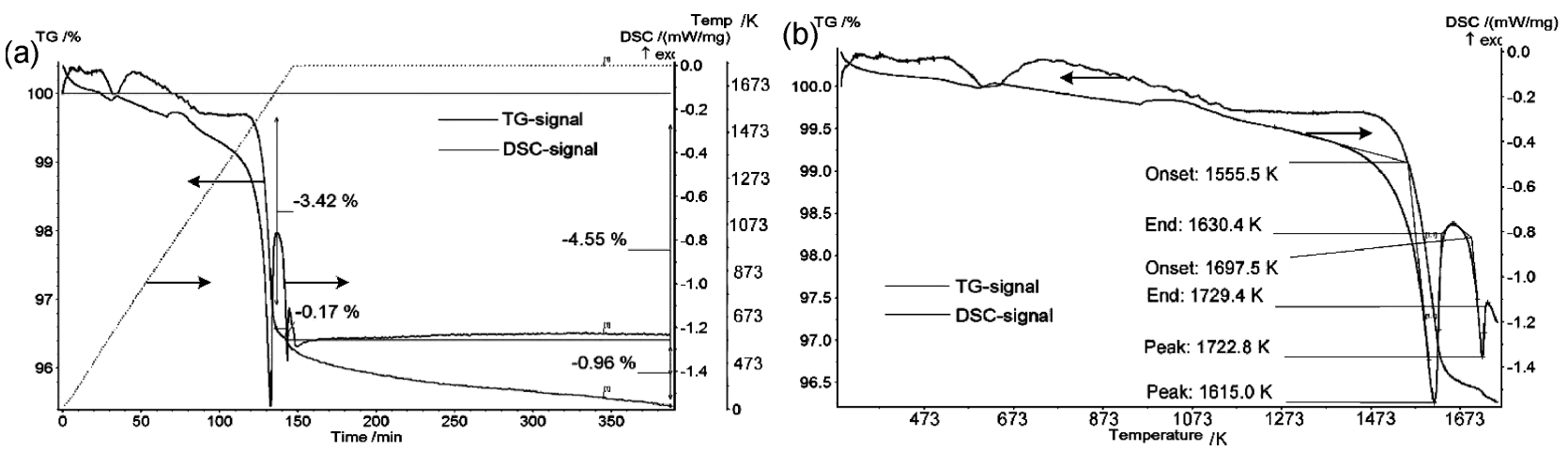

Fig. 7. TGA-DSC analysis of hematite ore (Particle size: $125-250 \mu \mathrm{m}$ ) (a) as a function of time, (b) as a function of temperature. 
degree is shown in Table 5. In the table, $\mathrm{T}_{\mathrm{Fe}} \%$ denotes weight percentage of total iron in the sample, $\mathrm{Fe}^{2+} \%$, and $\mathrm{Fe}^{3+} \%$ are the weight percentages of $\mathrm{Fe}^{2+}$ and $\mathrm{Fe}^{3+}$ in the sample, respectively. According to the composition of the raw material, the elemental $\mathrm{Fe}$ is completely in the form of $\mathrm{Fe}_{2} \mathrm{O}_{3}$ in the raw material. Therefore the original oxygen percentage in the sample can be calculated with the weight percentage of the total iron in the sample. On the other hand, the oxygen weight loss by decomposition can be calculated with the weight percentage of $\mathrm{Fe}^{2+}$ in the sample. Finally, the equivalent reduction degree can be evaluated by Eq. (1). The rough product composition is calculated by assuming that $\mathrm{FeO}$ is generated until the transformation from $\mathrm{Fe}_{2} \mathrm{O}_{3}$ to $\mathrm{Fe}_{3} \mathrm{O}_{4}$ is completed. According to the assumption and theoretical evaluation, the partially decomposed hematite ore is mainly composed of magnetite and wüstite and the percentage of wüstite goes up with increasing temperature. Generally, the equivalent reduction degree increases with the increase of temperature. The equivalent reduction degree at $1773 \mathrm{~K}$ is slightly higher than that at $1673 \mathrm{~K}$ by $0.87 \%$. However, it increases strongly from the temperature of $1773 \mathrm{~K}$ to $1873 \mathrm{~K}$. At $1873 \mathrm{~K}$, the decomposition reaction of $\mathrm{Fe}_{2} \mathrm{O}_{3}$ takes place intensively resulting in $16.4 \%$ equivalent reduction degree. It indicates that the thermal decomposition of magnetite becomes faster above $1773 \mathrm{~K}$. It confirms the results of theoretical evaluation as shown in Fig. 2 . The hematite ore at $1873 \mathrm{~K}$ were melted down completely, while the samples were still in solid state at $1673 \mathrm{~K}$ and

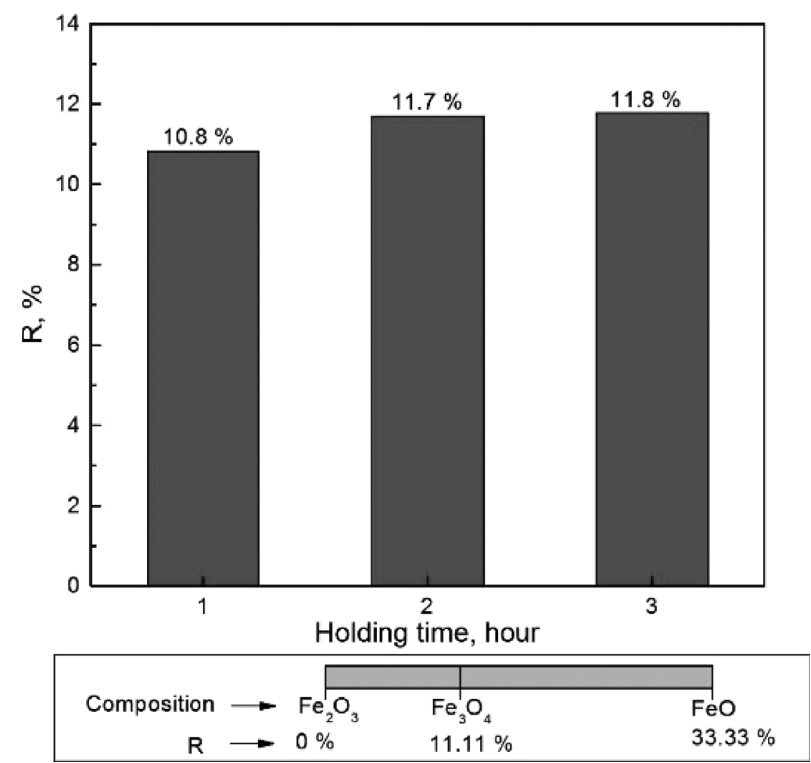

Fig. 8. Iron ore equivalent reduction degree in different holding time at $\mathrm{T}=1673 \mathrm{~K}$.

\section{$1773 \mathrm{~K}$.}

\subsection{Experiments in the HTDF}

With TGA-DSC and horizontal tube furnace, a sharp weight loss stage has been detected during the thermal decomposition of hematite. At the end of the sharp weight loss stage, hematite decomposed to magnetite completely at the experimental temperature about $1723 \mathrm{~K}$ of smelting cyclone. It would play an important role in the total prereduction degree in the smelting cyclone. However, the residence time of the iron ore particles in the cyclone reactor is much shorter than the time investigated in the TGA-DSC and horizontal tube furnace. Whether the sharp weight loss stage is present in the smelting cyclone and how fast the thermal decomposition will proceed during the sharp weight loss stage were not clear and could not be deduced from the above results. Therefore, the thermal decomposition behaviour of individual particle was further studied with the HDTF, in which the hematite ore particle was injected into the reactor by the injection probe and reaction took place during the flying time in the reactor. The reaction gas in the cyclone reactor mainly consists of $\mathrm{CO}, \mathrm{CO}_{2}, \mathrm{H}_{2}, \mathrm{H}_{2} \mathrm{O}$ and $\mathrm{N}_{2}$. Through analyzing the off-gas composition from the cyclone reactor, it was found that $\mathrm{CO}_{2}$ is over $60 \%$ and $\mathrm{N}_{2}$ is around $5-10 \%$. In this study, both $\mathrm{CO}_{2}$ and $\mathrm{N}_{2}$ were used as inert gas to study the thermal decomposition behaviour of hematite ore. In order to verify the effect of the structure of the gas molecular on the equivalent reduction degree, monoatomic gas of Ar was also used. The equivalent reduction degree of the collected samples was also calculated based on the analysis by chemical titration.

\subsubsection{Effect of Temperature and the Type of Gas}

Figure 9 shows the effect of temperature and the type of gas on the thermal decomposition of iron ore particles. The experiments of thermal decomposition of hematite ore in $\mathrm{CO}_{2}$ gas were carried out at $1550 \mathrm{~K}, 1600 \mathrm{~K}, 1650 \mathrm{~K}, 1750 \mathrm{~K}$ and $1800 \mathrm{~K}$. The particle size was in the range of $45-53 \mu \mathrm{m}$. The particle residence time in the hot zone was maintained at $2020 \mathrm{~ms}$. In order to study the influence of different inert gas on the equivalent reduction degree of iron ore, the experiments have also been carried at three selected temperature: $1650 \mathrm{~K}, 1750 \mathrm{~K}$ and $1800 \mathrm{~K}$ in $\mathrm{N}_{2}$ gas and Ar gas.

The results show that the equivalent reduction degree of hematite ore increases with the increase of temperature for all inert gases used. But the difference of thermal decomposition between the temperature of $1750 \mathrm{~K}$ and $1800 \mathrm{~K}$ is quite small. At the three temperatures of $1650 \mathrm{~K}, 1750 \mathrm{~K}$ and $1800 \mathrm{~K}$, the equivalent reduction degrees of hematite ore particles in $\mathrm{CO}_{2}$ gas (solid circle) are much higher than

Table 5. Equivalent reduction degree of hematite ore in horizontal furnace.

\begin{tabular}{|c|c|c|c|c|c|c|c|c|c|}
\hline \multirow{2}{*}{$\mathrm{T}(\mathrm{K})$} & \multirow{2}{*}{$\mathrm{t}(\mathrm{h})$} & \multicolumn{3}{|c|}{ Chemical titration result (wt\%) } & \multirow{2}{*}{$\mathrm{R}(\%)$} & \multicolumn{3}{|c|}{ Composition (wt\%)\# } & \multirow{2}{*}{$\begin{array}{c}\text { Physical } \\
\text { state }\end{array}$} \\
\hline & & $\mathrm{T}_{\mathrm{Fe}}$ & $\mathrm{Fe}^{2+}$ & $\mathrm{Fe}^{3+}$ & & $\mathrm{Fe}_{2} \mathrm{O}_{3}$ & $\mathrm{Fe}_{3} \mathrm{O}_{4}$ & $\mathrm{FeO}$ & \\
\hline 1673 & 2 & 69.1 & 24.3 & 44.9 & 11.7 & 0.0 & 93.0 & 2.3 & Solid \\
\hline 1773 & 2 & 68.9 & 26.0 & 42.9 & 12.6 & 0.0 & 88.9 & 5.8 & Solid \\
\hline 1873 & 2 & 69.5 & 34.3 & 35.2 & 16.4 & 0.0 & 73.1 & 21.4 & Liquid \\
\hline
\end{tabular}




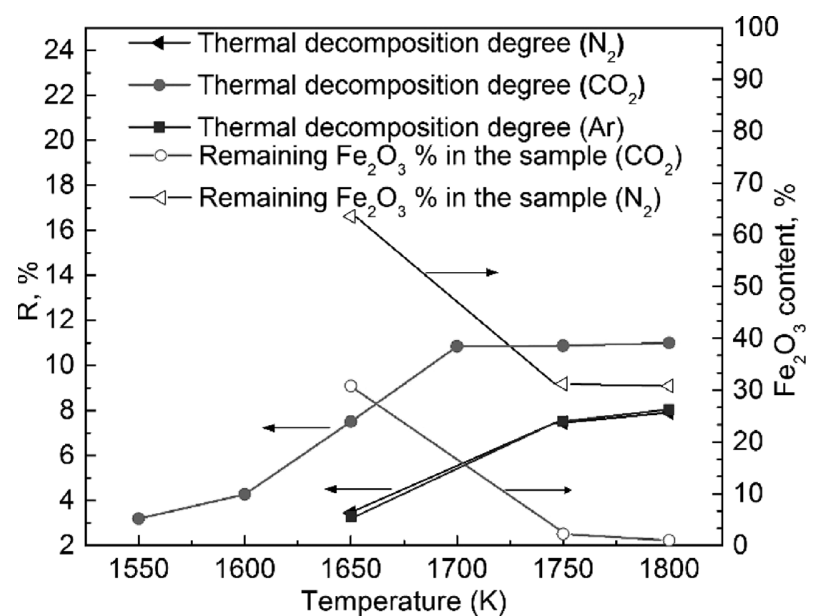

Fig. 9. Thermal decomposition of hematite ore in $\mathrm{Ar}, \mathrm{CO}_{2}$ and $\mathrm{N}_{2}$ at different temperatures.

that in $\mathrm{N}_{2}$ gas (solid triangle). The difference of the equivalent reduction degrees in the two gases $\left(\mathrm{CO}_{2}\right.$ and $\left.\mathrm{N}_{2}\right)$ is about $3-4 \%$. By estimation of the composition of the iron ore sample, it shows that the remaining hematite content in the sample with $\mathrm{N}_{2}$ gas is much higher than that in the sample with $\mathrm{CO}_{2}$ gas. For example, at $1750 \mathrm{~K}$, the $\mathrm{Fe}_{2} \mathrm{O}_{3}$ in the product which was decomposed in $\mathrm{N}_{2}$ gas was about $31.2 \%$, while the $\mathrm{Fe}_{2} \mathrm{O}_{3}$ in the product which was decomposed in $\mathrm{CO}_{2}$ gas was only about $2.3 \%$. The experimental results in Ar gas (solid square) as shown in the figure are almost the same with the results in $\mathrm{N}_{2}$ gas. It is because $\mathrm{CO}_{2}$ is an asymmetric diatomic molecule, while $\mathrm{N}_{2}$ is a symmetric molecule and Ar is a monatomic molecule. The structure of molecules is important for molecular radiation - emission and absorption which occurs only when an atom makes a transition from one state with a certain amount of energy to a state with lower (higher) energy, respectively. Homonuclear diatomic molecules like $\mathrm{N}_{2}$ and $\mathrm{O}_{2}$ and monatomic molecules like Ar do not have radiative capability for its symmetrical distribution of charges. Compared to $\mathrm{N}_{2}$ and $\mathrm{Ar}, \mathrm{CO}_{2}$ has strong thermal radiation capacity. That is also why $\mathrm{CO}_{2}$ gas is the most important greenhouse gas. Therefore a fine particle is heated up more quickly in $\mathrm{CO}_{2}$ gas through thermal radiation than in $\mathrm{N}_{2}$ and $\mathrm{Ar}$ gases.

The experiments carried out at $1673 \mathrm{~K}, 1773 \mathrm{~K}$ and 1873 $\mathrm{K}$ in the horizontal furnace were selected to compare with the experiments carried out at $1650 \mathrm{~K}, 1700 \mathrm{~K}, 1750 \mathrm{~K}$ and $1800 \mathrm{~K}$ in the HTDF as shown in Fig. 10. It was found that the sharp weight loss stage still exists in the HTDF during the particle flying time through the hot zone. However, the sharp weight loss stage was not completed at $1650 \mathrm{~K}$. The equivalent reduction degree of iron ore in $\mathrm{CO}_{2}$ gas is $7.5 \%$ and in $\mathrm{N}_{2}$ gas is $3.5 \%$ which are far below the result of $11.7 \%$ in the horizontal tube furnace. At $1700 \mathrm{~K}, 1750 \mathrm{~K}$ and $1800 \mathrm{~K}$, the equivalent reduction degrees of $10.8 \%$, $10.9 \%$ and $11.0 \%$ of iron ore in the HTDF with $\mathrm{CO}_{2}$ are quite close to the result of $12.6 \%$ at $1773 \mathrm{~K}$ in the horizontal furnace. It indicates that almost the whole sharp weight loss stage observed in TGA-DSC tests was achieved at the temperature from $1700 \mathrm{~K}$ to $1800 \mathrm{~K}$ in the HTDF, although the residence time of iron ore particles were much shorter than the holding time in the horizontal furnace. This may be

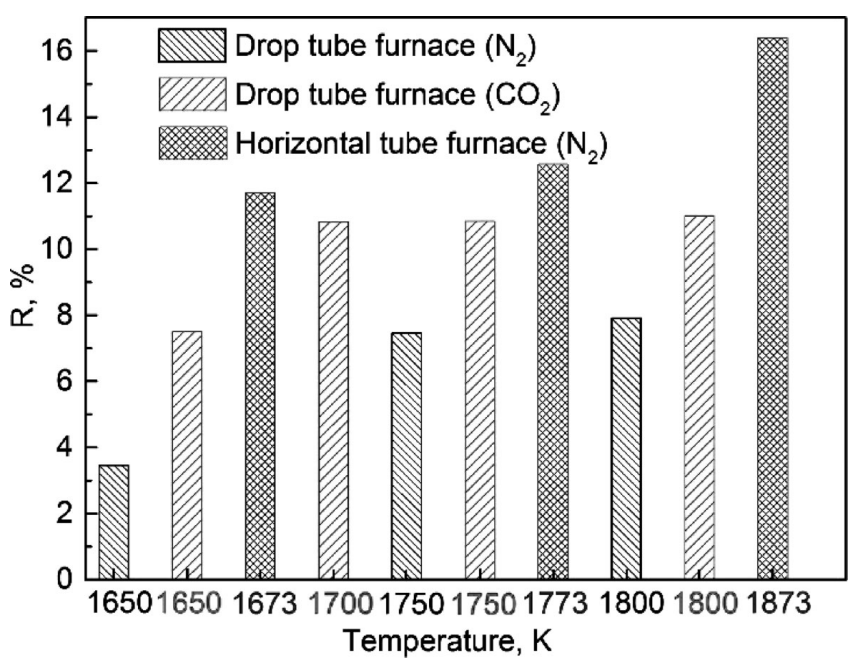

Fig. 10. Comparison of thermal decomposition of hematite ore in the horizontal furnace and the HDTF, residence time: $2020 \mathrm{~ms}$ in HDTF, 2 hours in horizontal tube furnace.

caused by two reasons. Firstly, the hematite ore in HTDF is moving individual particles, having much better and more favorite kinetic conditions than in the horizontal tube furnace where they are packed and steady with lower relative moving velocity from the gas. Secondly, the thermal decomposition rate of iron ore at the sharp weight loss stage is extremely fast.

\subsubsection{Effect of Residence Time}

How fast the thermal decomposition rate of iron ore is at its sharp weight loss stage could not be estimated from the results with TGA-DSC analysis and the horizontal furnace. Although TGA-DSC analysis provided the online report of weight loss as a function of time, the heating rate $(10 \mathrm{~K} / \mathrm{min}$.) in the TGA-DSC analyzer was different from the heating rate in the smelting cyclone. Therefore, further experiments were carried out in the HTDF with different residence time. The results of chemical analysis of the sample are shown in Table 6. Both $\mathrm{N}_{2}$ gas and $\mathrm{CO}_{2}$ gas were separately used. The residence time of the flying iron ore particle was adjusted by varying the gas flow rate. In the first part, the temperature in the hot zone was set to $1650 \mathrm{~K}$ and $1800 \mathrm{~K}$ with the inert gas of $\mathrm{N}_{2}$. The particle size was in the range of $45-53$ $\mu \mathrm{m}$. Two residence time of $2020 \mathrm{~ms}$ and $970 \mathrm{~ms}$ was tested. It was found that the decomposition degree of hematite ore in the $\mathrm{N}_{2}$ gas goes up with the increase of residence time. The equivalent reduction degree in $2020 \mathrm{~ms}$ (e.g. 5\% at $1650 \mathrm{~K})$ is about $1-1.5 \%$ higher than that in $970 \mathrm{~ms}(e . g$. $3.5 \%$ at $1650 \mathrm{~K}$ ) in $\mathrm{N}_{2}$ gas. In the smelting cyclone the bulk gas is mainly composed of $\mathrm{CO}_{2}$ gas which has a strong thermal radiation capacity. Therefore, more experiments have been carried out in $\mathrm{CO}_{2}$ gas. It was found that the equivalent reduction degree did not change by changing the residence time. For example, at $1750 \mathrm{~K}$, the residence time of iron ore particles was verified from $210 \mathrm{~ms}$ to $2020 \mathrm{~ms}$, but the equivalent reduction degree of iron ore was all around $10.8 \%$ which is very close to $11 \%$ (the complete decomposition of $\mathrm{Fe}_{2} \mathrm{O}_{3}$ ).

Therefore, the residence time in the HTDF has influence on the equivalent reduction degree of iron ore with $\mathrm{N}_{2}$, but 
Table 6. Thermal decomposition of hematite ore with different residence time in HTDF (particle size: $45-53 \mu \mathrm{m}$ ).

\begin{tabular}{|c|c|c|c|c|c|c|c|c|c|c|}
\hline \multirow{2}{*}{ Gas } & \multirow{2}{*}{$\mathrm{T}(\mathrm{K})$} & \multirow{2}{*}{$\mathrm{t}(\mathrm{ms})$} & \multicolumn{3}{|c|}{ Chemical titration result (wt\%) } & \multirow{2}{*}{$\mathrm{R}(\%)$} & \multicolumn{2}{|c|}{ Composition (wt\%)\# } & \multirow{2}{*}{$\begin{array}{l}\mathrm{t}_{\mathrm{du}} \\
\text { (h) }\end{array}$} & \multirow{2}{*}{$\begin{array}{c}\mathrm{m}_{\text {sample }} \\
\text { (g) }\end{array}$} \\
\hline & & & $\mathrm{T}_{\mathrm{Fe}}$ & $\mathrm{Fe}^{2+}$ & $\mathrm{Fe}^{3+}$ & & $\mathrm{Fe}_{2} \mathrm{O}_{3}$ & $\mathrm{Fe}_{3} \mathrm{O}_{4}$ & & \\
\hline \multirow{4}{*}{$\mathrm{N}_{2}$} & \multirow{2}{*}{1650} & 2020 & 64.4 & 9.7 & 54.7 & 5.0 & 50.5 & 40.1 & $\sim 5$ & $3-4$ \\
\hline & & 970 & 64.6 & 6.7 & 57.9 & 3.5 & 63.6 & 27.7 & $\sim 5$ & $3-4$ \\
\hline & \multirow{2}{*}{1800} & 2020 & 65.9 & 17.4 & 48.5 & 8.8 & 19.5 & 72.2 & $\sim 5$ & $3-4$ \\
\hline & & 970 & 65.5 & 15.5 & 49.9 & 7.9 & 30.8 & 62.1 & $\sim 5$ & $3-4$ \\
\hline \multirow{3}{*}{$\mathrm{CO}_{2}$} & 1750 & 2020 & 66.0 & 21.3 & 44.7 & 10.8 & 3.0 & 88.2 & $\sim 5$ & $3-4$ \\
\hline & 1750 & 970 & 67.2 & 21.9 & 45.3 & 10.9 & 2.4 & 90.6 & $\sim 5$ & $3-4$ \\
\hline & 1750 & 210 & 66.8 & 21.2 & 45.6 & 10.6 & 10.0 & 82.5 & $\sim 5$ & $3-4$ \\
\hline
\end{tabular}

$* \mathrm{~m}_{\text {sample }}$ is weight of collected samples; $\mathrm{t}_{\mathrm{du}}$ means duration of each experiment at the reaction temperature. \# calculated based on titration analysis.

Table 7. Thermal decomposition of hematite ore in different particle size.

\begin{tabular}{|c|c|c|c|c|c|c|c|c|c|c|c|}
\hline \multirow{2}{*}{ Gas } & \multirow{2}{*}{$\mathrm{d}_{\mathrm{p}}(\mu \mathrm{m})$} & \multirow{2}{*}{$\mathrm{t}(\mathrm{ms})$} & \multicolumn{3}{|c|}{ Chemical titration result (wt\%) } & \multirow{2}{*}{$\mathrm{R}(\%)$} & \multicolumn{3}{|c|}{ Composition (wt\%)\# } & \multirow{2}{*}{$\begin{array}{l}\mathrm{t}_{\mathrm{du}} \\
(\mathrm{h})\end{array}$} & \multirow{2}{*}{$\begin{array}{c}\mathrm{m}_{\text {sample }} \\
\text { (g) }\end{array}$} \\
\hline & & & $\mathrm{T}_{\mathrm{Fe}}$ & $\mathrm{Fe}^{2+}$ & $\mathrm{Fe}^{3+}$ & & $\mathrm{Fe}_{2} \mathrm{O}_{3}$ & $\mathrm{Fe}_{3} \mathrm{O}_{4}$ & $\mathrm{FeO}$ & & \\
\hline \multirow{4}{*}{$\mathrm{CO}_{2}$} & $38-45$ & \multirow{2}{*}{970} & 66.6 & 21.8 & 44.8 & 10.9 & 1.7 & 90.4 & 0.0 & $\sim 5$ & $3-4$ \\
\hline & $75-90$ & & 66.0 & 21.0 & 45.0 & 10.6 & 4.7 & 87.0 & 0.0 & $\sim 5$ & $3-4$ \\
\hline & $90-125$ & \multirow{2}{*}{210} & 66.5 & 21.4 & 45.1 & 10.7 & 3.5 & 88.5 & 0.0 & $\sim 7$ & $5-6$ \\
\hline & $125-250$ & & 64.9 & 20.1 & 44.8 & 10.3 & 6.7 & 83.1 & 0.0 & $\sim 5$ & $3-4$ \\
\hline
\end{tabular}

${ }^{*} \mathrm{~m}_{\text {sample }}$ is weight of collected samples; $\mathrm{t}_{\mathrm{du}}$ means duration of each experiment at the reaction temperature. \# calculated based on titration analysis.

has no influence on the equivalent reduction degree of iron ore with $\mathrm{CO}_{2}$. It is mainly caused by the gas radiation properties, which makes the $\mathrm{CO}_{2}$ gas very effective for heat transfer to the particles. In other words, the particle heating rate in $\mathrm{N}_{2}$ gas would be the rate controlling step of the ore thermal decomposition. In the $\mathrm{CO}_{2}$ gas, the studied range of residence time did not affect the equivalent reduction degree, and what's more the sharp weight loss stage could be partly achieved in $210 \mathrm{~ms}$ and no further change of equivalent reduction degree could be detected during the residence time between $210 \mathrm{~ms}$ to $2020 \mathrm{~ms}$.

\subsubsection{Effect of Particle Size}

The experiments have been conducted with different particle sizes of the hematite ore in $\mathrm{CO}_{2}$ gas. The average temperature of the hot zone was controlled to $1750 \mathrm{~K}$. The experiments were divided into two groups: small particle and large particle. The residence time of the smaller particles was $970 \mathrm{~ms}$ and that of the larger particles was $210 \mathrm{~ms}$. The particle sizes in the first (small) group were in the range of 38-45 $\mu \mathrm{m}$ and $75-90 \mu \mathrm{m}$ and in the second (large) group were in the range of $90-125 \mu \mathrm{m}$ and $125-250 \mu \mathrm{m}$. The results are listed in Table 7. It can be seen that in all the studied particle size groups of $38-250 \mu \mathrm{m}$, the equivalent reduction degree of iron ore is in the range of $10.3-11.3 \%$. The small deviation can be neglected. Therefore, the particle size below $250 \mu \mathrm{m}$ does not have significant influence on the equivalent reduction degree of the hematite ore in the HDTF when the inert gas is $\mathrm{CO}_{2}$. On the other hand, for the difference of particle gravity, the residence time of the larger particles was shorter than the smaller particles. The results proved again that with $\mathrm{CO}_{2}$ gas, residence time is not a sig-

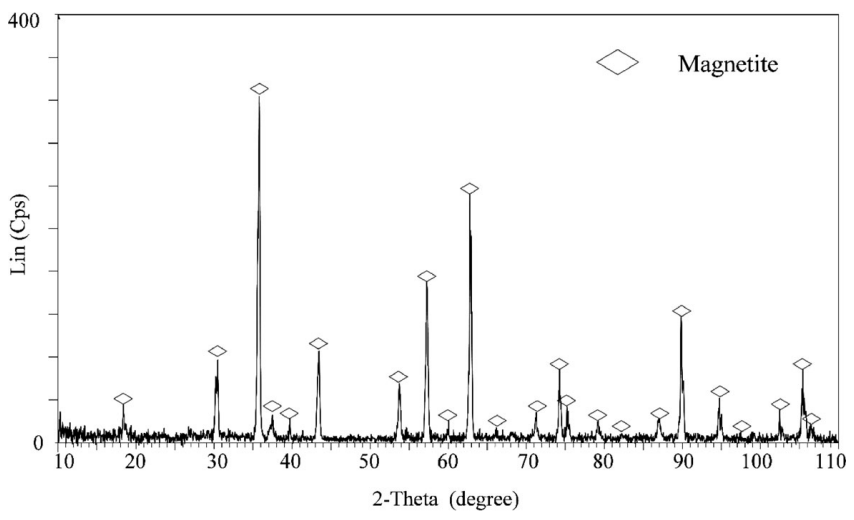

Fig. 11. XRD pattern of reacted iron ore sample at $1750 \mathrm{~K}$ in $\mathrm{CO}_{2}$.

nificant factor for the thermal decomposition behaviour of fine iron ore particles in the HTDF.

The sample of $90-125 \mu \mathrm{m}$ in Table 7 was analysed by XRD to identify the phases in the product as shown in Fig. 11. The figure gives the peak positions and intensities of the identified phases. This confirms fully the analytical results of chemical titration. The main phase in the reacted iron ore sample is magnetite and the phases of hematite and wüstite are either not present (wüstite) or too small to be detected (hematite).

\section{Conclusions}

In this paper, the thermal decomposition behaviour of hematite ore has been studied through theoretical and experimental methods. The experimental study has been carried 
out with the TGA-DAC analyzer, the horizontal tube furnace and the drop tube furnace (HTDF). The equivalent reduction degree of collected samples from horizontal furnace and HTDF were determined by chemical titration. The results were helpful for the further study of the kinetics of the melting and reduction mechanism of iron ore in the next stage. The conclusions are as follows:

- From the theoretical calculation, $\mathrm{Fe}_{2} \mathrm{O}_{3}$ is the most unstable iron oxide among the three iron oxides, while $\mathrm{FeO}$ is the most stable one. In an open system with flowing inert gas (the released $\mathrm{O}_{2}$ is removed continuously), the intensive thermal decomposition of $\mathrm{Fe}_{2} \mathrm{O}_{3}$ is likely to take place above $1473 \mathrm{~K}$ and the thermal decomposition of $\mathrm{Fe}_{3} \mathrm{O}_{4}$ is possible to speed up above $1773 \mathrm{~K}$.

- From TGA-DSC analysis, it is found that a sharp weight loss stage appeared on the TG curve in the range of temperature of 1473-1573 K. A big trough was found in the DSC curve at the same time. It was caused by the intensive decomposition of hematite. The result is in accordance with the theoretical estimation.

- From the experimental results in the horizontal furnace, the accurate equivalent reduction degree of hematite at a given temperature and holding time was obtained. The sharp weight loss stage observed in TGA-DSC test was achieved in all the studied temperatures in the horizontal tube furnace in 2 hours. Generally, the equivalent reduction degree of hematite increases with the increase of temperature. No significant difference was observed between the results at $1673 \mathrm{~K}$ and $1773 \mathrm{~K}$. However, the equivalent reduction degree of hematite at $1873 \mathrm{~K}$ was much higher than that at $1773 \mathrm{~K}$. It confirms that the thermal decomposition of magnetite could be accelerated above $1773 \mathrm{~K}$.

- From the study of in-flight thermal decomposition within HTDF, it was found that sharp weight loss stage which was observed in the TGA-DSC experiments could be partly achieved in the HTDF at high temperatures especially in the $\mathrm{CO}_{2}$ gas. The fine iron ore particles could be heated up faster in $\mathrm{CO}_{2}$ gas than in $\mathrm{N}_{2}$ and Ar gas due to the strong radiation properties (emission and absorption) of $\mathrm{CO}_{2}$ gas.

- No significant influence of particle size and residence time on the equivalent reduction degree could be observed in the HTDF, when the particle diameter is smaller than $250 \mu \mathrm{m}$ in the $\mathrm{CO}_{2}$ gas. At $1750 \mathrm{~K}$ in $\mathrm{CO}_{2}$ gas, the equivalent reduction degree of iron ore in HTDF is around $10.8 \%$ which is slightly lower than the value $12.6 \%$ obtained in horizontal furnace (holding time 2 hours).

\section{Acknowledgments}

This research was carried out at Delft University of Technology and was financially supported by the Materials innovation institute $\mathrm{M} 2 \mathrm{i}$ (www.m2i.nl) under the project M41.5.09327. The authors would like to express their thanks to Mr. Jan van der Stel and Mr. Jeroen Link from Tata Steel Europe (IJmuiden) for fruitful discussions and providing process data for this study. The first author acknowledges the China Scholarship Council (CSC) for providing the scholarship during this research at Delft University of technology.

\section{REFERENCES}

1) I. O. Lee, M. K. Shin, M. Cho, H. G. Kim and H. G. Lee: ISIJ Int., 42 (2002), S33.

2) A. Orth, N. Anastasijevic and H. Eichberger: Miner. Eng., 20 (2007), 854.

3) W. Peter and B. Christopher: A Sectoral Approach, Agreement and Mechanism (SAAM) for the Mitigation of Greenhouse Gas Emissions in Japan's Iron and Steel Industry, Climate Strategies 2011, UK, (2011), 13

4) C. Feilmayr, A. Thurnhofer, F. Winter, H. Mali and J. Schenk: ISIJ Int., 44 (2004), 1125.

5) K. Piotrowski, K. Mondalb, T. Wiltowski, P. Dydod and G. Rizeg: Chem. Eng. J., 137 (2007), 73.

6) F. Tsukihashi, K. Kato and T. Soma: ISIJ Int., 22 (1982), 688

7) J. Link: Rev. Métall., 106 (2009), 398.

8) K. Meijer, C. Guenther and R. J. Dry: METEC Conf., Verlag Stahleisen, Düsseldorf, (2011), 1.

9) H. L. Gilles and C. W. Clump: Ind. Eng. Chem. Proc. DD., 9 (1970), 194.

10) Y. Nakamura, M. Ito and H. Ishikawa: Plasma Chem. Plasma Process., 1 (1981), 149.

11) A. Habermann and F. W. H. Hofbauer: ISIJ Int., 40 (2000), 935

12) Y. K. Rao: Stoichiometry and Thermodynamics of Metallurgical Processes, Cambridge Univ. Press, Cambridge, (1985), 883.

13) R. M. Charles and J. G. Geoffrey: Energ. Fuel., 7 (1993), 928.

14) B. Richelieu, C. Michael and L. Edward: Fuel, 82 (2003), 1893.

15) M. Saito, M. Sadakata, M. Sato and T. Soutome: Combust. Flame, 87 (1991), 1. 